\title{
Determinants of uterine aging: lessons from rodent models
}

\author{
KONG ShuangBo $^{1,2 \dagger}$, ZHANG Shuang $^{1,2 \dagger}$, CHEN YongJie ${ }^{1,2}$, WANG WeiXiang ${ }^{1}$, \\ WANG Bing Yan ${ }^{1}$, CHEN Q $i^{1}$, DUAN EnKui ${ }^{1 *} \&$ WANG HaiBin ${ }^{1 *}$ \\ ${ }^{1}$ State Key Laboratory of Reproductive Biology, Institute of Zoology, Chinese Academy of Sciences, Beijing 100101, China; \\ ${ }^{2}$ Graduate University of Chinese Academy of Sciences, Beijing 100039, China
}

Received April 25, 2012; accepted June 26, 2012

\begin{abstract}
The uterus is an indispensable organ for the development of a new life in eutherian mammals. The female mammalian reproductive capacity diminishes with age. In this respect, the senescence of uterine endometrium is convinced to contribute to this failure. This review focuses on the physiological function of the uterus and the related influence of aging mainly in rodent models. A better understanding of the underlying mechanisms governing the process of uterine aging is hoped to generate new strategies to prolong the reproductive lifespan in humans.
\end{abstract}

determinants, uterine aging, rodent models

Citation: $\quad$ Kong S B, Zhang S, Chen Y J, et al. Determinants of uterine aging: lessons from rodent models. Sci China Life Sci, 2012, 55: 687-693, doi: $10.1007 / \mathrm{s} 11427-012-4356-1$

In mammals, the female reproductive capacity diminishes with age. A progressive decrease of litter size has been described in polytocous animals, such as rats [1-3], mice [4-7], golden hamsters [8], and rabbits [9]. More importantly, this phenomenon of continuous decline of fecundity with age has also been confirmed in women over 35 years old [10-12]. The success of reproduction in eutherian mammals requires the uterus, a unique organ in the viviparity compared to other organisms ensuring full development of the new life in the maternal body [13]. The endometrial environment of uteri is proved to be one of the critical aspects to determine the reproductive capacity [14] and uterine factor has been proved to be critical for the decline of fecundity in both rodents and humans [4,15]. Most of the available information on uterine aging derives from studies on rats and mice [16]. In these species, life span is short and aging animal model can be easily established. This review focuses on the physiological function of the uterus and the

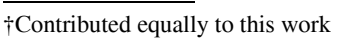

*Corresponding author (email: hbwang@ioz.ac.cn; duane@ioz.ac.cn) related influence of aging mainly in rodent models.

\section{Uterine physiological role in normal repro- ductive events}

In females, the Müllerian ducts develop into the reproductive tract, including the oviduct and uterus [17]. In mice, the uterus is evident at E16.5 and in humans between the 9th and 12th weeks of pregnancy [18]. In mice, the gestation length is about $20 \mathrm{~d}$ when counted from the day of vaginal plug formation (day 1). The main biological events occurred within the uteri are embryo implantation, decidualization, placentation and labor [19-21], which mainly under the influence of ovarian progesterone and estrogen [22]. A preovulatory estrogen surge induces remarkable proliferation of uterine epithelial cells on day 1 [23,24], while rising levels of progesterone together with preimplantation estrogen secreted on the morning of day 4 induce stromal cell proliferation to establish an optimal milieu for blastocyst attach- 
ment to the uterine lining [25]. The initiation of implantation in mice is characterized by a localized increase in uterine vascular permeability at the site of the blastocyst attachment, which occurs in the midnight of day 4 of pregnancy and can be visible by intravenous injection of Chicago blue dye (blue reaction) [20]. Coincidently, stromal cells immediately surrounding the implanting blastocyst undergo extensive proliferation and subsequently differentiate into specialized cells that are polyploidy, and this process is known as decidualization [26]. This extensive cell proliferation and polyploidy event occurs in a well-organized manner. It firstly takes place at the antimesometrial side around the embryo on day 6 , which is defined as primary decidual zone (PDZ) and then extends to the stromal cells next to the PDZ forming a fully developed zone around the PDZ, termed the secondary decidual zone (SDZ) [27]. This living embryo induced decidualization can also be mimicked by the application of artificial stimuli to a receptive pseudopregnant uterus, or one that has been appropriately primed by ovarian steroids, though not totally identical [28]. Although the decidua is a transient tissue, decidual cells are critical regulators of uterine remodeling, maternal immune response, uterine angiogenesis and early embryonic growth, which are critical for the transition to the formation of a functional placenta. From the mid-gestation, the embryos obtain nutrients essential for growth from the placenta vasculature, and the maternal vessel changes its characteristic benefit for sufficient mutual exchange of the nutrition and waste. The maternal endothelial cells are replaced by the trophoblast cell types at the maternal-fetal interface and the uterine radial arteries are modified by the invasion trophoblast cell to supply adequate maternal blood flow to the implantation site [29]. Parturition is the culmination of mammalian reproduction, which is a task essential for survival of the species and facilitated by the myometrial contractility. During the pregnancy, the uterine quiescence is maintained through a sustained high level of progesterone [30]. Prior to the labor, a decrease in progesterone levels or functional progesterone withdrawal synergizes with other contractile mediators to disrupt the myometrial relaxation resulting in efficient expulsion of the fetus [31].

\section{Uterine aging contributes to decreased re- productive capacity}

According to reproductive output, previous studies have delineated three stages in the reproductive lifespan of experimental rodents: (i) the period of maximum litter size, called the plateau period, which lasts for about 7 months; (ii) the period of declining litter size from approximately 8-15 months, and (iii) the stage of cessation of reproductive output $[4,7]$. The first point to be considered is the extent to which the reproductive decline is due to the failure of aging uteri to maintain the embryo. The evidence has come mostly from the examination of the uteri of old and middle-aged pregnant mice.

Recording the size of litter born to female mice caged continuously with a male, it has been proved that the litter size dropped significantly until to about two in the last litter. Then the female mice would not give birth any more though they were still left with the male. After the uteri of these mice were examined, placental or embryonic remains were found in some individual. Most importantly, counts of corpora lutea showed the normal released eggs at each ovulation near the time of death. This suggested that embryos were implanted but not being maintaining to term. Examination of the uteri of pregnant mice during the phase of declining litter size also showed increased number of regressing implantations [7,32]. It appeared that there is some failure of the uterus to support the growth of new life. However the possibility of a fault in the blastocyst, which may lead to poor postimplantation development, cannot be ruled out in these experimental designs. This point has been investigated by reciprocal embryo transfer between young and old animals $[33,34]$. It was found that the ova from old mice did as well as these from the young, and ova from the young mice cannot survival well in the uteri of the aging mice. These experiments support the uterine origin of the decreased reproductive capacity.

Another approach to address this issue is the transplantation of whole ovaries from the young mice to the old and vice versa [35,36]. Ovaries from the young mice failed to restore the reproductive output of the old mice, though the oestrous cycles reappeared. At the same time in the situation of ovaries from the old mice transplanted to the young ones, there was still almost no pregnancy success. This indicated that both the ovary and the uterus contribute to reproductive cessation in the old female, although the evidence suggested that it is the uterus which is primarily responsible, especially in the early phase of reproductive decline.

The situation in human is more complicated [37], much debate exists whether ovarian or uterine factors are primarily responsible for the age-related decline in fertility. The IVF and donor egg programs has provided a more direct means of investigating the relative contribution of the uterus and oocyte to human reproductive senescence. These researches convinced the importance of uterine factors [38], though the oocyte quality is the primary determinant [39-41]. All female mammals are born with a limited follicle pool [42], which will support the reproductive lifespan of the individual. In old women, the decline in fertility is followed by the menopause, which is caused by exhaust of ova in the ovaries about two thirds of the way through life $[43,44]$, whereas the cessation of reproductive activity in other female mammals is due to failure of the uterus, whilst the ovary still has available ova. Autopsy of very old female mouse reveals the presence of ova, although the number drops obviously as the female gets older, so the number of ova at birth is sufficient to last through the lifetime in mice 
[45]. Unlike other mammals, women use up all their ova by atresia and ovulation by the time they have reached middle age [44]. This is due to that the loss of ovarian follicles with advancing age is bi-exponential [46], with an accelerated rate of decline beginning (on average) in the latter half of the fourth decade of life $[42,47]$ (Table 1). Interestingly, if the initial rate of follicular atresia were to be sustained (i.e., no acceleration phase), it is estimated menopause would not be reached until the mid-70s [44]. Therefore, in human it is the ovary factor that mainly determines the reproduction aging, while the uterus also contributes to the decline of the reproduction in older females, as the implantation efficiency in older women is lower than that in young women and that increased maternal age is a risk factor for pregnancy-associated complications, including preterm birth and preeclampsia $[15,48]$.

\section{Altered hormonal profile during aging}

The uterus is mainly under the influence of ovarian steroid hormones [20], and the age-related modification of uteri reflects the change of ovarian function and levels of the progesterone and estrogen. From the middle age, the menstrual cycles of women and the estrous cycles of rodents begin to irregular. In rats, irregular cycles begin in 10-12 months old and the incidence of abnormal cycles increases with age [49]. As the rats grow old, they would be in a state of either constant estrus, characterized by mature ovarian follicles, high serum levels of estradiol, and an "estrogenized" uterus, or "pseudopregnancy," characterized by the presence of many corpora lutea and a well-developed "secretary" uterus.

The 24-month-old rats in constant estrus have an increase in uterine weight, largely due to increased luminal fluid, while uterine epithelium is columnar, and stroma and myometrium are thicker with an increase in collagen fibrils, owing to a sustained stimulation of estrogen. Uteri of older rats (30 months) in persistent diestrus appear to be progesterone stimulated, exhibiting cuboidal epithelium and some spontaneous decidual cells in the stroma [50]. Eventually the old rats become anestrus. The ovaries and uterus are atrophic, no mature follicles are present, and the uterus resembles that from an ovariectomized or immature rat, which resulted from low circulation level of steroid hormone [51]. Despite that the hormone profile changes account for the uterine abnormality, the senescing endometrium does not respond to ovarian hormones as well as that in young animals [52].

\section{Histological characteristics of aging uteri}

The most notable change in the aging uterus was a dramatic increase in uterine collagen [16,53,54]. This collagen deposition in aging mice was stimulated by estrogen [55]. By contrast, the reduction in collagen and the loss of endometrial collagen during pregnancy in multiparous animals could be attributed to high levels of progesterone [56]. In rats, the total amount of uterine collagen did not increase in these young animals after estrogen stimulation, though the collagen synthesis in the uterus was induced, indicating that the collagen degradation was also active. The distribution of this collagen deposition was mainly in endometrial stroma and smooth muscle [57]. Previous studies have confirmed the increased fibrosis with age in the uterus of the rats [50], mice [58] and rabbits [59]. There was an age-related increase in the number of mast cells in the uterus, which was known to be associated with fibrotic processes [60]. Although the uterus of most rodent species increases in size with age, in postmenopausal women the uterus atrophies as ovarian steroid hormones diminishes [61].

The two functional layer, epithelium and stroma, exhibit cellular morphological change in old mice, contributing to the decreased pregnancy success. In the uterus, the blastocysts firstly connect with the epithelium to establish intimate relationship with the maternal tissue, and this process is called attachment. During the normal implantation, the uterine lumen and associated epithelial cell morphology are dynamically altered [62]. The uterine lumen changes from being irregular and branched in cross-section to slit-like, with which surface microvilli lose their tall, regular profiles to become shorter and more irregular in shape [63]. At the time of implantation, the lateral epithelial surface are closely apposed that the intercellular distance is about $15 \mathrm{~nm}$, so that uterine lumen is closed [14]. When the uteri are fixed in Bouin's fluid, the apposed luminal surfaces are pulled apart and the epithelial surface has a corrugated appearance. This

Table 1 Comparison of female reproductive characteristics between humans and mice ${ }^{\text {a) }}$

\begin{tabular}{|c|c|c|}
\hline & Human & Mouse \\
\hline No. of follicles at birth & $\sim 1000000$ & $\sim 75000$ \\
\hline No. of follicles at puberty & $\sim 200000$ & $\sim 60000$ \\
\hline Follicle attrition each cycle & $\begin{array}{l}\text { Bi-exponentially changed, before } 37 \text {, follicles } \\
\text { decline at a steady rate; after } 37 \text {, decline at an } \\
\text { accelerated rate until menopause }[44]\end{array}$ & $\begin{array}{l}\text { With a constant rate, about } 1000 \text { each cycle } \\
{[40,45]}\end{array}$ \\
\hline Reproductive span & $\sim 30$ years & $\sim 12$ months \\
\hline Menopause & $\sim 50$ & $N / A^{a)}$ \\
\hline
\end{tabular}

a) N/A, not applicable. 
closure can be preserved in glutaraldehyde fixation. This closure is due to a change in the adhesiveness property of the epithelial surface, which can be regulated by the estrogen [64]. However, in the old mice, these changes have some abnormal performance. First, the orientation of lumen was not usually as well organized as in the young animals; second, there was little evidence of corrugation in the epithelial surfaces [65], which further proved that the lumen is open in old mice fixed by the glutaraldehyde fixation. The same situation was noted in the old rat [66]. In senescing golden hamsters, both closure and implantation were deferred by approximately $12 \mathrm{~h}$ and luminal closure was found only around the implanting embryos [67]. Where embryos were not present, the lumen remained open and branched and luminal epithelial cells had tall, regular microvilli which did not contact microvilli from the opposing epithelial border.

Some other cell organelles are also detected to be different in the young versus old animals. Rough endoplasmic reticulum was less extensive in tissue from older rats and appeared as short fragments compared to the extended network found in tissue from the young animals, although free ribosomes and polysomes were extremely dense in some areas of the older tissue. Golgi cisternae were sometimes dilated in older animals but were in general similar to those seen in young rats. Secondary lysosomes, with contents of variable electron density, were often increased in the older animals [16]. The stroma cells, which need to be differentiated to decidual cells, also had different appearances between the young and old animals. There was an increase in lipofuscin deposits in the cytoplasm of some aged stromal cells as well as an increase in the amount of collagen and in the number of lymphocytes, plasma cells, and macrophages [66]. The collagen was the most obvious difference. The density of collagen fibrils increased with age, especially in the basal areas of the endometrium, where the degree of cellularity was markedly diminished and collagen bundles formed large, closely packed aggregates. The majority of fibrils measured was between 35 and $60 \mathrm{~nm}$ in diameter, and loosely arranged in the subluminal areas and more aggregated deeper into the tissue [16].

\section{Functional defects in senescing endometrium}

During the implantation, the sensitive uteri can accept the competent blastocyst, which involves the crosstalk between the trophectoderm and uterine epithelium. The epithelium will transduce the message to the underneath stroma to initiate the decidualization process [68]. As mentioned above, the uterine epithelium in old rodent has abnormal appearance during the uterine preparation to enter the receptivity, thus will fail to send the message properly and the decidualization will not form as well as in young animals $[69,70]$. With the progression of pregnancy in old animals, more embryos were resorbed, reinforcing that there is something wrong within the uterine decidua.

The decidual stimulus by the blastocyst can be mimicked artificially either by crushing the uterus with forceps or by intraluminal oil injection [71]. No decidual reaction was frequently observed in elder mice after oil injection, whereas the young ones responded. The animals in which the uteri were crushed can respond positively, but the size was smaller in the old animals [71]. A decrease in the response has also been described in aging rodents as assessed by other parameters, including weight increase, the histological appearance, alkaline phosphatase activity, and amounts of DNA, protein, and glycogen [58,66,71-75]. Remodeling of the extracellular matrix during decidualization appeared to be a requirement and function of decidual cells in human and rodent uteri [76]. The abnormally deposited extracellular matrix, such as collagen, appeared to prevent the formation of extensive junctional complexes and interdigitation, which may impair the stromal-decidual transformation and subsequent placental development [16].

Using a uterine endometrium specific senescence mouse model with uterine selective deletion of p53 [77], previous studies have showed senescence-associated growth restriction and preterm labor caused by increased levels of phosphorylated Akt and p21 in the knockout decidual tissue $[78,79]$. This senescence program of the p53 knockout decidual tissue would lead to increased levels of COX2derived PGs, which affected the contractility of the uterus directly (Figure 1), not through the indirect luteolysis. Preterm birth has been a global health concern for far too long and the etiology is multifactorial. These risk factors are known to contribute to the cellular senescence process and the genetic evidence proved that p53's downstream, mammalian target of rapamycin complex 1 (mTORC1) signaling plays a key role in uterine senescence and the timing of birth [80]. As aging is a cause of cellular senescence [81,82], and decidual senescence is proved to be associated with premature delivery [79], it is conceivable that uterine senescence imposed by maternal aging carries an increased risk for problematic parturition. In humans, the epidemiologic study indicates that increased maternal age is correlated with preterm delivery $[15,83,84]$, and women of higher maternal age, who use assisted reproductive technologies to achieve pregnancy, may experience a higher incidence of preterm birth even when receiving oocytes from young donors $[85,86]$.

\section{Summary}

Previous studies from a variety of animal models have revealed the uterine factor contributed to the poor pregnancy success in old individuals. In old animals, the abnormality of uteri is caused by the ovarian hormone profile change and cell automatic defect accompanied with the senescence. 


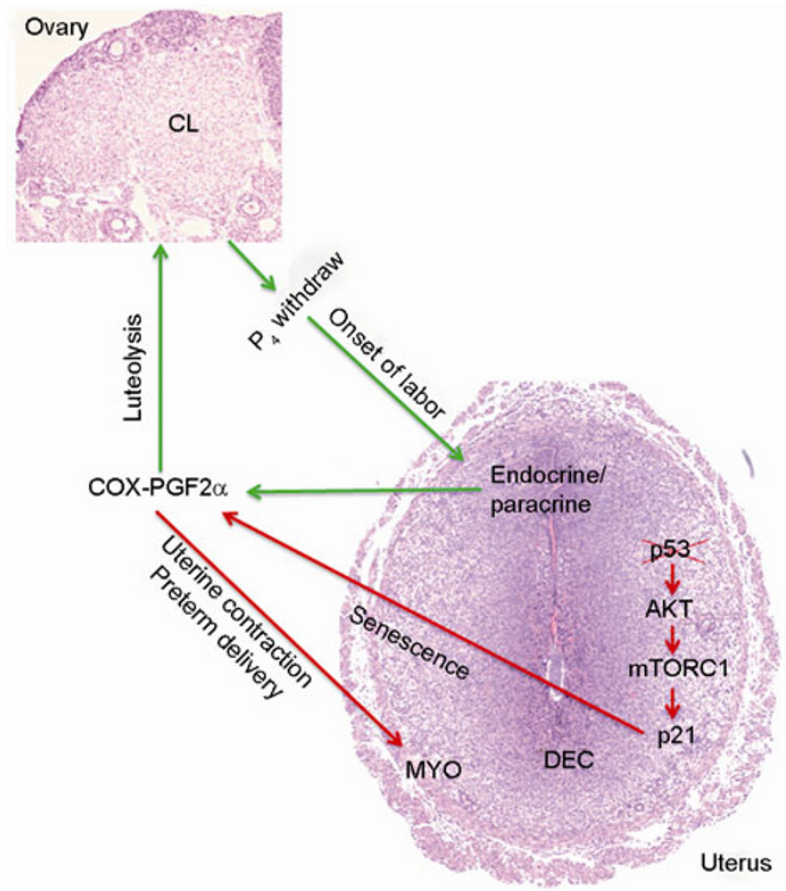

Figure 1 Uterine senescence and parturition onset. In normal parturition process, endocrine and paracrine factors would activate the COX-PGF $2 \alpha$ axis in uteri and this prostaglandin product targets the ovarian corpusluteum to lysis. The main pregnancy-maintained hormone progesterone from the corpus luteum decreases sharply, leading to the initiation of labor program in uteri. Loss of p53 in uterine endometrium induces decidual cell senescence, via increased levels of phosphorylated Akt and upregulated expression of $\mathrm{p} 21$. This defect leads to earlier activation of the COX-PGF ${ }_{2 \alpha}$ axis, inducing preterm labor. Green line indicates the cascade of parturition program in wild type case, and red line indicates this in p53 knockout uterus. $\mathrm{CL}$, corpus luteum; $\mathrm{P}_{4}$, progesterone; DEC, decidual tissue; MYO, Myometrium.

Aging uterus has significant morphological change, consequently hampering many physiological pregnancy events, like the decidualization and labor onset. Therefore, the senescence research about the uterus should be paid more attention to increase the reproductive quality. Although ovarian functions, such as ovulation and hormone secretion, are assumed to be altered with aging and one cause of decreased fecundity in humans [48], there has been less investigative focus on uterine aging and its consequences for fertility in humans, so uterine senescence warrants further investigation.

Work incorporated in this article was partially supported by the National Basic Research Program of China (Grant Nos. 2011 CB944401 and 2010CB945002) and the National Natural Science Foundation of China (Grant Nos. 30825015 and 81130009).

1 Ingram D L, Mandl A M, Zuckerman S. The influence of age on litter-size. J Endocrinol, 1958, 17: 280-285

2 Day J R, La Polt P S, Morales T H, et al. An abnormal pattern of embryonic development during early pregnancy in aging rats. Biol Reprod, 1989, 41: 933-939

3 Miller A E, Wood S M, Riegle G D. The effect of age on reproduction in repeatedly mated female rats. J Gerontol, 1979, 34: $15-20$

4 Biggers J D, Finn C A, Mc L A. Long-term reproductive performance of female mice. I. Effect of removing one ovary. J Reprod Fertil, 1962, 3: 303-312

5 Finn C A. Embryonic death in aged mice. Nature, 1962, 194: 499-500

6 Finn C A. Reproductive capacity and litter size in mice: effect of age and environment. J Reprod Fertil, 1963, 6: 205-214

7 Biggers J D, Finn C A, Mc L A. Long-term reproductive performance of female mice. II. Variation of litter size with parity. J Reprod Fertil, 1962, 3: 313-330

8 Parkening $\mathrm{T}$ A, Soderwall A L. Delayed fertilization and preimplantation loss in senescent golden hamsters. Biol Reprod, 1975, 12: 618-631

9 Adams C E. Ageing and reproduction in the female mammal with particular reference to the rabbit. J Reprod Fertil Suppl, 1970, 12: $1-16$

10 Edwards R G, Morcos S, Macnamee M, et al. High fecundity of amenorrhoeic women in embryo-transfer programmes. Lancet, 1991, 338: 292-294

11 Stovall D W, Toma S K, Hammond M G, et al. The effect of age on female fecundity. Obstet Gynecol, 1991, 77: 33-36

12 Menken J, Trussell J, Larsen U. Age and infertility. Science, 1986, 233: 1389-1394

13 Dey S K, Lim H, Das S K, et al. Molecular cues to implantation. Endocr Rev, 2004, 25: 341-373

14 Finn $\mathrm{C}$ A. The ageing uterus and its influence on reproductive capacity. J Reprod Fertil Suppl, 1970, 12: 31-38

15 Cnattingius S, Forman M R, Berendes $\mathrm{H} \mathrm{W}$, et al. Delayed childbearing and risk of adverse perinatal outcome. A population-based study. JAMA, 1992, 268: 886-890

16 Mulholland J, Jones C J. Characteristics of uterine aging. Microsc Res Tech, 1993, 25: 148-168

17 Kobayashi A, Behringer R R. Developmental genetics of the female reproductive tract in mammals. Nat Rev Genet, 2003, 4: 969-980

18 Lim H J, Wang H. Uterine disorders and pregnancy complications: insights from mouse models. J Clin Invest, 2010, 120: 1004-1015

19 Rossant J, Cross J C. Placental development: lessons from mouse mutants. Nat Rev Genet, 2001, 2: 538-548

20 Dey S K. Focus on implantation. Reproduction, 2004, 128: 655-656

21 Mesiano S, Welsh T N. Steroid hormone control of myometrial contractility and parturition. Semin Cell Dev Biol, 2007, 18: 321-331

22 Wang H, Dey S K. Roadmap to embryo implantation: clues from mouse models. Nat Rev Genet, 2006, 7: 185-199

23 Huet Y M, Andrews G K, Dey S K. Modulation of c-myc protein in the mouse uterus during pregnancy and by steroid hormones. Prog Clin Biol Res, 1989, 294: 401-412

24 Huet-Hudson Y M, Andrews G K, Dey S K. Cell type-specific localization of $\mathrm{c}$-myc protein in the mouse uterus: modulation by steroid hormones and analysis of the periimplantation period. Endocrinology, 1989, 125: 1683-1690

25 Tranguch S, Daikoku T, Guo Y, et al. Molecular complexity in establishing uterine receptivity and implantation. Cell Mol Life Sci, 2005, 62: 1964-1973

26 Das S K. Cell cycle regulatory control for uterine stromal cell decidualization in implantation. Reproduction, 2009, 137: 889-899

27 Tan J, Raja S, Davis M K, et al. Evidence for coordinated interaction of cyclin D3 with p21 and cdk6 in directing the development of uterine stromal cell decidualization and polyploidy during implantation. Mech Dev, 2002, 111: 99-113

28 Lim H, Paria B C, Das S K, et al. Multiple female reproductive failures in cyclooxygenase 2-deficient mice. Cell, 1997, 91: 197-208

29 Adamson S L, Lu Y, Whiteley K J, et al. Interactions between trophoblast cells and the maternal and fetal circulation in the mouse placenta. Dev Biol, 2002, 250: 358-373 
30 Ratajczak C K, Muglia L J. Insights into parturition biology from genetically altered mice. Pediatr Res, 2008, 64: 581-589

31 Challis J R, Lye S J, Gibb W. Prostaglandins and parturition. Ann N Y Acad Sci, 1997, 828: 254-267

32 Sugiyama T. Reproductive power of mother mice of different ages. Acta Sch Med Univ Kioto, 1961, 37: 172-179

33 Boot L M, Muhlbock O. The ovarian function in old mice. Acta Physiol Pharmacol Neerl, 1954, 3: 463-464

34 Talbert G B, Krohn P L. Effect of maternal age on viability of ova and uterine support of pregnancy in mice. J Reprod Fertil, 1966, 11: 399-406

35 Jones E C, Krohn P L. Orthotopic ovarian transplantation in mice. J Endocrinol, 1960, 20: 135-146

36 Krohn P L. Review lectures on senescence. II. Heterochronic transplantation in the study of ageing. Proc R Soc Lond B Biol Sci, 1962, 157: 128-147

37 Klein J, Sauer M V. Assessing fertility in women of advanced reproductive age. Am J Obstet Gynecol, 2001, 185: 758-770

38 Rosenwaks Z, Davis O K, Damario M A. The role of maternal age in assisted reproduction. Hum Reprod, 1995, 10: 165-173

39 Sauer M V, Paulson R J, Lobo R A. Reversing the natural decline in human fertility. An extended clinical trial of oocyte donation to women of advanced reproductive age. JAMA, 1992, 268: 1275-1279

40 Navot D, Drews M R, Bergh P A, et al. Age-related decline in female fertility is not due to diminished capacity of the uterus to sustain embryo implantation. Fertil Steril, 1994, 61: 97-101

41 Navot D, Bergh P A, Williams M A, et al. Poor oocyte quality rather than implantation failure as a cause of age-related decline in female fertility. Lancet, 1991, 337: 1375-1377

42 Oktem O, Urman B. Understanding follicle growth in vivo. Hum Reprod, 2010, 25: 2944-2954

43 Younis J S. Ovarian aging and implications for fertility female health. Minerva Endocrinol, 2012, 37: 41-57

44 Finn C A. Reproductive ageing and the menopause. Int J Dev Biol, 2001, 45: 613-617

45 Mandl A M, Shelton M A. quantitative study of oocytes in young and old nulliparous laboratory rats. J Endocrinol, 1959, 18: 444-450

46 Faddy M J, Gosden R G, Gougeon A, et al. Accelerated disappearance of ovarian follicles in mid-life: implications for forecasting menopause. Hum Reprod, 1992, 7: 1342-1346

47 McGee E A, Hsueh A J. Initial and cyclic recruitment of ovarian follicles. Endocr Rev, 2000, 21: 200-214

48 Carolan M. The graying of the obstetric population: implications for the older mother. J Obstet Gynecol Neonatal Nurs, 2003, 32: 19-27

49 Lu K H, Hopper B R, Vargo T M, et al. Chronological changes in sex steroid, gonadotropin and prolactin secretions in aging female rats displaying different reproductive states. Biol Reprod, 1979, 21: 193-203

50 Hsueh A J, Erickson G F, Lu K H. Changes in uterine estrogen receptor and morphology in aging female rats. Biol Reprod, 1979, 21: 793-800

51 Huang H H, Steger R W, Bruni J F, et al. Patterns of sex steroid and gonadotropin secretion in aging female rats. Endocrinology, 1978, 103: 1855-1859

52 Finn C A, Martin L. The cellular response of the uterus of the aged mouse to oestrogen and progesterone. J Reprod Fertil, 1969, 20: 545-547

53 Loeb L, Suntzeff V, Burns E L. The effects of age and estrogen on the stroma of vagina, cervix and uterus in the mouse. Science, 1938 , 88: 432-433

54 Burack E, Wolfe J, Lansing W, et al. The effect of age upon the connective tissue of the uterus, cervix, and vagina of the rat. Cancer Res, 1941, 1: 227-235

55 Suntzeff V, Babcock R, Loeb L. Reversibility of hyalinization in the mouse uterus produced by injections of estrogen, and the changes in the mammary gland and ovaries after cessation of injections. Am J
Cancer, 1940, 38: 217-223

56 Dyer R F, Sodek J, Heersche J N. The effect of 17 beta-estradiol on collagen and noncollagenous protein synthesis in the uterus and some periodontal tissues. Endocrinology, 1980, 107: 1014-1021

57 Rolle G K, Charipper H A. The effects of advancing age upon the histology of the ovary, uterus and vagina of the female golden hamster (Cricetus auratus). Anatom Rec, 1949, 105: 281-297

58 Gosden R G. Effects of age and parity on the breeding potential of mice with one or two ovaries. J Reprod Fertil, 1979, 57: 477-487

59 Maurer R R, Foote R H. Uterine collagenase and collagen in young and ageing rabbits. J Reprod Fertil, 1972, 30: 301-304

60 Atkins F M, Clark R A. Mast cells and fibrosis. Arch Dermatol, 1987, 123: $191-193$

61 Woessner J F Jr. Age-related changes of the human uterus and its connective tissue framework. J Gerontol, 1963, 18: 220-226

62 Enders A C, Schlafke S. A morphological analysis of the early implantation stages in the rat. Am J Anatomy, 1967, 120: 185-225

63 Murphy C R. The plasma membrane of uterine epithelial cells: structure and histochemistry. Prog Histochem Cytochem, 1993, 27: $1-66$

64 Nilsson O. Estrogen-induced increase of adhesiveness in uterine epithelium of mouse and rat. Exp Cell Res, 1966, 43: 239-241

65 Martin L, Finn C A, Carter J. Effects of progesterone and oestradiol-17 beta on the luminal epithelium of the mouse uterus. $\mathrm{J}$ Reprod Fertil, 1970, 21: 461-469

66 Craig S S. Effect of age upon uterine response to deciduagenic stimulus. Acta Anat (Basel), 1981, 110: 146-158

67 Thorpe L W, Connors T J, Soderwall A L. Closure of the uterine lumen at implantation in senescent golden hamsters. J Reprod Fertil, 1974, 39: 29-32

68 Lejeune B, Van Hoeck J, Leroy F. Transmitter role of the luminal uterine epithelium in the induction of decidualization in rats. $J$ Reprod Fertil, 1981, 61: 235-240

69 Maibenco H C, Krehbiel R H. Reproductive decline in aged female rats. J Reprod Fertil, 1973, 32: 121-123

70 Finch C E, Holinka C F. Aging and uterine growth during implantation in C57BL/6J mice. Exp Gerontol, 1982, 17: 235-241

71 Finn $\mathrm{C}$ A. The initiation of the decidual cell reaction in the uterus of the aged mouse. J Reprod Fertil, 1966, 11: 423-428

72 Holinka C F, Finch C E. Age-related changes in the decidual response of the C57BL/6J mouse uterus. Biol Reprod, 1977, 16: 385-393

73 Pollard R M, Finn C A. The effect of ovariectomy at puberty on cell proliferation and differentiation in the endometrium of the aged mouse. Biol Reprod, 1974, 10: 74-77

74 Shapiro M, Talbert G B. The effect of maternal age on decidualization in the mouse. J Gerontol, 1974, 29: 145-148

75 Blaha G C. Effects of age, treatment, and method of induction on deciduomata in the golden hamster. Fertil Steril, 1967, 18: 477-485

76 Mulholland J, Aplin J D, Ayad S, et al. Loss of collagen type VI from rat endometrial stroma during decidualization. Biol Reprod, 1992, 46: 1136-1143

77 Feng Z, Hu W, Teresky A K, et al. Declining p53 function in the aging process: a possible mechanism for the increased tumor incidence in older populations. Proc Natl Acad Sci USA, 2007, 104: 16633-16638

78 Li Y, Dowbenko D, Lasky L A. AKT/PKB phosphorylation of p21Cip/WAF1 enhances protein stability of p21Cip/WAF1 and promotes cell survival. J Biol Chem, 2002, 277: 11352-11361

79 Hirota Y, Daikoku T, Tranguch S, et al. Uterine-specific p53 deficiency confers premature uterine senescence and promotes preterm birth in mice. J Clin Invest, 2010, 120: 803-815

80 Hirota $\mathrm{Y}$, Cha J, Yoshie M, et al. Heightened uterine mammalian target of rapamycin complex 1 (mTORC1) signaling provokes preterm birth in mice. Proc Natl Acad Sci USA, 2011, 108: 18073-18078 
81 Collado M, Blasco M A, Serrano M. Cellular senescence in cancer and aging. Cell, 2007, 130: 223-233

82 Campisi J, d'Adda di Fagagna F. Cellular senescence: when bad things happen to good cells. Nat Rev Mol Cell Biol, 2007, 8: 729-740

83 Roberts C L, Algert C S, March L M. Delayed childbearing--are there any risks? Med J Aust, 1994, 160: 539-544

84 Balasch J, Gratacos E. Delayed childbearing: effects on fertility and the outcome of pregnancy. Fetal Diagn Ther, 2011, 29: 263-273

85 Krieg S A, Henne M B, Westphal L M. Obstetric outcomes in donor oocyte pregnancies compared with advanced maternal age in in vitro fertilization pregnancies. Fertil Steril, 2008, 90: 65-70

86 Nelson S M, Lawlor D A. Predicting live birth, preterm delivery, and low birth weight in infants born from in vitro fertilisation: a prospective study of 144,018 treatment cycles. PLoS Med, 2011, 8: e1000386

Open Access This article is distributed under the terms of the Creative Commons Attribution License which permits any use, distribution, and reproduction in any medium, provided the original author(s) and source are credited. 